\title{
Procedimento para ensino de mandos e para promover variação na topografia das respostas em crianças autistas ${ }^{1}$
}

Mariana Chernicharo Guimarães. New England Center for Children

Nilza Micheletto. Pontifícia Universidade Católica de São Paulo

\section{Resumo}

Este estudo avaliou um procedimento para ensinar e produzir variabilidade em topografias de mando para duas crianças com autismo. Os objetivos foram: 1) ensinar novas topografias de mando por um procedimento de fading out do modelo verbal, 2) verificar se novas topografias de mando eram emitidas por generalização recombinativa, e 3) ensinar variabilidade pelo reforçamento direto do variar. Cinco topografias de mando foram ensinadas por um procedimento de fading out do modelo ecoico. Para ensinar variabilidade, usou-se o esquema Lag no qual reforçamento era contingente à resposta ser diferente das anteriores. O esquema Lag foi aumentado gradualmente. Os resultados mostraram que as crianças aprenderam as cinco topografias de mando. Novas topografias emergiram por generalização recombinativa, i.e., combinações entre topografias de mando ensinadas com novos objetos e partes abstraídas das diferentes topografias recombinadas em novas topografias. Variabilidade foi produzida só quando variações foram reforçadas após o ensino das topografias de mando.

Palavras-chaves: variabilidade de resposta; criatividade; aprendizagem por discriminação; mando; autismo.

\section{Abstract}

Procedures to teach mand frames and to promote variation of the responses in children with autism. This study evaluated a procedure to teach and produce variability in mand topographies to two children with autism. The objectives of the study were: 1) teaching new mand frames by a procedure of fading out the verbal model, 2) verifying whether new mand frames were emitted by recombinative generalization, and 3) teaching variability by direct reinforcing variation. Five mand frames were taught by a procedure of fading out the echoic model. To teach variability, a Lag schedule was used in which reinforcement was delivered contingent on the response being different from the previous ones. The Lag schedule was increased gradually. The results showed that the children learned the five mand frames. New mand topographies emerged from recombinative generalization, i.e., combinations between taught mand frames with new objects and parts of different mand frames recombined in new frames. Variability was produced only when variation was reinforced after mand frames were taught.

Keywords: response variability; creativity; discrimination learning; mand; autism.

\section{Resumen}

Procedimientos para enseñar respuestas de comandos y para promover la variación en la topografía de respuestas en niños autistas. El trabajo buscó evaluar un procedimiento para enseñar y producir variabilidad para dos niños autistas. Los objetivos del estudio fueron: 1) enseñarles nuevas topografías de comando por medio de un procedimiento de desvanecimiento del modelo verbal; 2) testear si se emiten nuevos comandos por generalización recombinativa, y 3) enseñarles variación por medio del reforzamiento directo de la variación. Se enseñaron cinco topografías de comando con un procedimiento de desvanecimiento del modelo ecoico. Para enseñar variabilidad, el programa Lag utilizado consistió en reforzar las respuestas que fueran diferentes a las anteriores. El programa Lag fue aumentado gradualmente. Los resultados mostraron que los niños aprendieron las cinco topografías de comando. Surgieron nuevas topografías de comando por generalización recombinativa, es decir, combinaciones entre topografias de comando enseñadas con nuevos objetos y elementos de comandos diferentes recombinados en nuevas topografías. Cuando se reforzó la variación, se produjo variabilidad, después de que se enseñaran las topografias de comando. Palabras clave: variabilidad de respuesta; creatividad; aprendizaje por discriminación; comando; autismo. 
Crianças diagnosticadas com transtorno do espectro autista (TEA), na maioria dos casos, não possuem um repertório verbal adequado: frequentemente apresentam muitas repetições (uma fala estereotipada), frases sem sentido dentro de um contexto e dificuldade em expressar claramente o que querem ou de interagir em uma conversa. Tais repertórios constituem o alvo de programas de ensino para tais crianças. Em muitos programas de treinamentos apontados por Sundberg e Michael (2001), aplica-se tecnologia comportamental no ensino do comportamento verbal. Nesses programas o foco é ensinar a criança a se comunicar com os cuidadores de uma maneira efetiva. Essas questões têm constituído o campo da linguagem. Na perspectiva da análise do comportamento, essa comunicação é descrita e explicada por meio do comportamento verbal, um tipo de comportamento operante.

No comportamento operante, "os homens agem sobre o mundo, modificam-no e são, por sua vez, modificados pelas consequências de sua ação" (Skinner, 1957, p. 1). No comportamento verbal, as ações humanas têm efeitos sobre outras pessoas que fornecem as consequências; tais ações são, portanto, efetivas na modificação do mundo apenas pela mediação de outra pessoa. No entanto, isso só ocorre quando o ouvinte e o falante, como parte de uma comunidade verbal, foram preparados para desempenhar ambos os papéis (Skinner, 1957). Identificando diferenças e semelhanças nos efeitos que as respostas verbais têm sobre os ouvintes que fornecem as consequências e nas condições antecedentes em que elas ocorrem, Skinner propôs uma classificação dessas contingências no que chamou de operantes verbais (mando, tato, ecóico, textual, transcrição e intraverbal). Na contingência classificada como mando, a resposta verbal emitida está sob o controle de condições motivacionais do falante, geradas por um estímulo aversivo ou um estado de privação, e está relacionada a um reforçador específico. Esse operante verbal beneficia o falante (Skinner, 1957).

Os mandos, objeto do presente estudo, são muito importantes para o início da aprendizagem do comportamento verbal de crianças. São comportamentos verbais prováveis de serem emitidos, podendo ocorrer a generalização mais rapidamente, porque estão sob controle de condições motivacionais (Sundberg \& Michael, 2001).

Observa-se que muito do comportamento verbal de crianças mais novas são tipicamente mandos, que produzem reforçadores incondicionados ou fortes reforçadores condicionados. Segundo Sundberg e Michael (2001), o mando propicia à criança ter algum tipo de controle no ambiente social e, indiretamente, também sobre o ambiente não social. $O$ valor do mando para o falante são suas consequências, como, por exemplo, conseguir objetos ou criar condições que não estão presentes. As características do controle no mando tornam-no relevante para ser ensinado para crianças autistas que, em geral, têm limites na comunicação.

Diante das dificuldades que muitos autistas têm em adquirir repertório verbal, vários estudos foram conduzidos, buscando-se ampliar este repertório com diferentes objetivos e procedimentos (Matson, Sevin, Box, Francis, \& Sevin, 1993; Taylor \& Harris, 1995; Williams, Donley, \& Keller, 2000).

Taylor e Harris (1995) ensinaram três crianças autistas a fazer a pergunta "o que é isso?", diante de fotos e objetos novos por meio do procedimento atraso de dica. Os resultados indicaram que os participantes aprenderam rapidamente a fazer a pergunta e generalizaram para outros objetos, pessoas e locais. Matson et al. (1993) compararam os efeitos do procedimento de apresentação de dica visual e sua gradual retirada (fading) com o procedimento de dica verbal com atraso, para aumentar as verbalizações que denominaram de "auto-iniciadas" (respostas verbais que ocorrem na ausência de estímulos discriminativos verbais antecedentes), como saudações: "obrigado", "dá licença", "oi" e "brinca comigo", para três crianças autistas. O procedimento de fading da dica visual ocorreu em passos: inicialmente, era apresentado um cartão com a palavra (e.g., "oi"), a seguir, o experimentador entrava na sala segurando o cartão, nos próximos passos o tamanho do cartão era diminuído até ser eliminado. No procedimento de tempo de atraso de dica verbal, o tempo de atraso entre a apresentação do estímulo (experimentador entrar na sala) e do modelo verbal era gradualmente aumentado em $2 \mathrm{~s}$ após respostas "auto-iniciadas" ou respostas de imitação do modelo (e.g., o pesquisador entrava na sala e esperava $2 \mathrm{~s}$ antes de falar o modelo "Oi"). Os resultados mostraram que ambos os procedimentos foram eficazes para aumentar o responder "iniciado" pela criança.

Esvanecimento [fading] do modelo verbal tem, também, sido utilizado para ensinar comportamento verbal (Lee, Sturmey, \& Fields, 2007; Romano, 2014; Williams et al., 2000). Williams et al. (2000) 
desenvolveram um procedimento para ensinar duas crianças autistas a fazerem perguntas sobre os objetos escondidos em caixas: "o que é isso?" - produzia a nomeação do objeto pelo experimentador; "Posso ver?" - era seguida pela apresentação do objeto e "Posso pegar?" - era seguida pela obtenção do objeto. Inicialmente, ensinaram a criança ecoar a pergunta apresentada como modelo e, posteriormente, foi feito um fading out do modelo verbal utilizando um delineamento de linha de base múltipla entre as três formas de resposta. As crianças, que na linha de base não faziam nenhum dos três tipos de perguntas, aprenderam as três: emitiram-nas durante a intervenção em frequência muito maior, e nos testes realizados em outros locais pela mãe se mantiveram nas sessões de follow up.

Além de ensinar topografias de comportamento verbal em diversas contingências por meio de diferentes procedimentos e avaliar a generalização de tais comportamentos para outros ambientes e pessoas, analistas do comportamento têm investigado fatores que favoreçam a ampliação do comportamento verbal que passa a ocorrer sob controle de estímulos novos, em formas não ensinadas (Goldstein, 1983; Hanna et al., 2011; Schreibman et al., 2015; Skinner, 1957; Striefel \& Wetherby, 1973), e no caso de crianças autistas, especialmente, investigam também procedimentos para alterar a fala estereotipada.

Skinner (1957) indicou que o comportamento novo pode ocorrer quando novas combinações não ensinadas de propriedades do ambiente podem ganhar controle sobre o comportamento verbal. No comportamento verbal, o reforçamento de unidades maiores, tais como a palavra, pode propiciar o estabelecimento de controle por unidades menores, tais como as sílabas ou letras. Assim recombinações de unidades de controle de estímulo em novas formas podem gerar comportamento verbal novo. O processo no qual o responder passa a ser controlado por novas combinações de componentes de estímulos que formavam outras combinações de estímulos previamente aprendidas é chamado de generalização recombinativa (Goldstein, 1983; Striefel \& Wetherby, 1973).

Goldstein (1983) ensinou crianças a dizerem sentenças compostas por pseudo palavras de uma sílaba que combinadas formavam frases com um sujeito e um verbo. Quatro palavras eram sujeito e quatro eram verbo que indicavam quatro ações diferentes. Quatro marionetes eram os sujeitos da ação. Cada marionete realizava, no treino, apenas uma ação. O experimentador dizia uma frase, que a criança deveria repetir, com duas palavras, uma relativa ao sujeito e outra à ação que a marionete estava realizando. Em testes, realizados após os treinos, foi verificado se as crianças, ao observarem a marionete realizando uma ação diferente da feita no treino, eram capazes de nomear o sujeito e a nova ação, fazendo frases que envolviam recombinações de sujeitos com ações não ensinadas. Todas as crianças responderam formando frases que envolviam recombinação.

O ensino de comportamento verbal pode se beneficiar das contribuições da área de generalização recombinativa e do planejamento de procedimentos que possam acelerar a ocorrência de comportamentos, não diretamente ensinados, por recombinação. Procedimentos que favoreçam generalização recombinativa podem potencializar a ocorrência de comportamento novo e ampliar a quantidade de topografias de respostas disponíveis para que o responder de forma variada possa ocorrer. Amplia-se assim a matéria prima necessária para que a seleção pelo reforço, entre várias formas verbais, seja possível.

Mesmo um repertório ampliado pode não ser suficiente para que a fala estereotipada de crianças autistas deixe de ocorrer, este aspecto deve ser avaliado durante o processo de ensino. Procedimentos de ensino de respostas verbais variadas têm sido investigados por diversos autores (Esch, Esch, \& Love, 2009; Lee, McComas, \& Jawor, 2002; Lee \& Sturmey, 2006; Romano, 2014; Susa \& Schlinger, 2012). De especial importância para o ensino dessas crianças são os procedimentos que reforçam diretamente o variar. Quando se reforça diretamente a variação, além do efeito fortalecedor de um conjunto de respostas, há também o efeito motivacional, o reforçamento pode manter em geral altos níveis de responder. O procedimento de extinção, apesar de produzir variação, enfraquece o responder e gera efeitos emocionais não desejáveis (Neuringer, Deiss, \& Olson, 2000).

O esquema de reforçamento do responder variado, denominado Lag, em que se reforçam respostas que são diferentes das emitidas anteriormente, tem sido utilizado para ensinar comportamento verbal variado. Lee et al. (2002) verificaram se o reforçamento contingente ao variar, utilizando um esquema de reforçamento Lag 1 que envolve reforçar a resposta que fosse diferente das emitidas anteriormente, poderia ser estendido ao comportamento verbal de autistas. Eles 
examinaram os efeitos do esquema Lag 1 no responder variado à questões sociais como "O que você quer fazer?" de três autistas, utilizando um delineamento de reversão ABA. Houve aumento na porcentagem de respostas verbais apropriadas e variadas para questões sociais para dois dos três participantes; quando houve retorno às condições de linha de base, ocorreu um decréscimo nessa porcentagem.

Lee e Sturmey (2006) replicaram o estudo de Lee et al. (2002), com três adolescentes, buscando verificar se a presença desses itens tangíveis (por exemplo, um $M \& M$ ) durante as sessões experimentais poderia interferir na variabilidade das respostas. O esquema de reforçamento Lag1 foi suficiente para aumentar a variabilidade das respostas à questão social para dois dos três participantes, quando foi controlada sistematicamente a presença dos itens.

Esch et al. (2009) fizeram uma replicação sistemática do estudo de Lee et al. (2002), e Lee e Sturney (2006), com o intuito de avaliar os efeitos do esquema Lag 1 para variabilidade vocal em crianças autistas não verbais. Participaram do estudo duas crianças com um repertório verbal bastante limitado, que emitiam rara e repetitivamente alguns sons. O comportamento vocal alvo foi definido como respostas que produziam sons de palavras. O esquema de reforçamento Lag 1 produziu um aumento sistemático nas vocalizações em duas crianças autistas, e um pequeno aumento na variabilidade dessas vocalizações. O retorno imediato à linha de base após o Lag 1 sugere, segundo os autores, que esquemas Lag maiores (exemplo, Lag 2 e Lag 3) poderiam aumentar a resistência a extinção.

Susa e Schlinger (2012) investigaram, com uma criança com diagnóstico de autismo, os efeitos do aumento de exigência de variabilidade de respostas verbais, utilizando esquema de reforçamento Lag que foi sendo aumento gradativamente de Lag 1 até Lag 3 (no qual respostas deveriam ser diferentes das três anteriores para serem reforçadas). Identificaram que à medida que a exigência aumenta, a variabilidade da resposta aumenta.

No presente estudo, buscou-se avaliar a efetividade de um procedimento de ensino de repertório verbal variado para crianças autistas. Foi avaliado: 1) se é possível ensinar novas topografias de mando de solicitação por meio de um procedimento de fading do modelo verbal, ampliando o número de topografias no repertório; 2) se novos mandos passam a ser emitidos por meio de generalização recombinativa quando objetos que não foram utilizados no ensino direto das topografias de mando são apresentados; e 3) se era possível, por meio de um esquema de reforçamento do variar progressivo, produzir respostas variadas de mando.

Algumas condições foram criadas para atender aos objetivos propostos neste estudo. Para ensino de mandos, testes de preferência foram realizados antes de cada sessão, buscando estabelecer condições motivacionais na situação de ensino em que reforçadores específicos poderiam ser produzidos pela emissão de mandos. Foram introduzidos objetos diferentes nos testes de preferência de forma a permitir avaliar se; durante o ensino das topografias, a emissão da topografia de mando ocorria com um novo objeto, por generalização recombinativa. Foi programado um aumento gradativo da exigência de variabilidade (Lag 1 ao 3) para verificar a amplitude de respostas variadas que poderiam ser produzidas com este aumento. Buscou-se reunir no procedimento de ensino condições identificadas em diversas áreas que investigam a produção de comportamento novo, visando favorecer a interação de condições potencialmente favorecedoras de tais comportamentos, geradas por diferentes processos comportamentais. A avaliação de um procedimento com tais características pode ajudar a superar limites de comunicação de crianças autistas, potencializando os efeitos de procedimento de ensino simples e exequíveis em situação de aplicação.

\section{Método}

\section{Participantes}

Duas crianças com diagnóstico de autismo, que estudavam em uma escola particular que trabalha com a inclusão de crianças com necessidades especiais, foram escolhidas por não apresentarem um repertório verbal de mando, de acordo com as observações feitas pela experimentadora e as entrevistas com as professoras.

P1 tinha 8 anos de idade e estudava em um módulo especializado para desenvolver algumas habilidades, como por exemplo ler as letras e números, se comportar adequadamente em sala de aula e etc, antes de passar para as séries da escola regular. Possuía um repertório verbal que possibilitava a interação com outras pessoas, e era descrito pela professora como uma criança que "fala na terceira pessoa 
Procedimento para ensino de mandos e para promover variação na topografia das respostas em crianças autistas

e tem uma boa memória, pois guarda tudo o que acontece, o que as pessoas falam e fazem". P1 constantemente repetia o que as pessoas falavam com ele, usava sempre as mesmas frases para se comunicar e não pedia independentemente os brinquedos e atividades que gostaria de fazer. P2 tinha 6 anos de idade, cursava a primeira série do ensino regular. Possuía um repertório verbal que Ihe permitia responder perguntas e, segundo relato da professora, "repete sempre a última palavra que disse". P2 interagia pouco com os colegas da sala, tinha dificuldades para pedir sobre o que gostaria de brincar ou fazer e esperava pela ajuda da professora para se comunicar com os colegas.

\section{Local e Material}

Foi utilizada uma sala de aula de $2 \mathrm{~m}^{2}$ da escola particular em que as crianças estudam equipada com uma cadeira, uma mesa, itens de preferência e folhas de registro.

\section{Procedimento}

Avaliação de Preferência. Antes do início de cada sessão, os participantes passaram por um procedimento de avaliação de preferência - Multiple Stimulus Without Replacement (MSWO) (DeLeon \& Iwata, 1996). O procedimento consistiu na apresentação de 10 objetos de forma aleatória e o participante tinha que escolher um objeto, que foi considerado o de maior preferência. Quando um objeto era escoIhido, este era retirado e eram reorganizados os objetos restantes e a criança tinha que fazer uma nova escolha, até terminarem todos os objetos disponíveis. Os cinco primeiros objetos escolhidos foram considerados os itens de maior preferência e eram utilizados naquela sessão. Os 10 objetos apresentados em cada sessão foram alterados aos poucos, procurando sempre trocar os objetos que não eram escolhidos e mantendo os cinco itens de maior preferência do participante a cada avaliação de preferência. Além disso, os testes foram planejados de forma a que fosse provável ser selecionado um objeto que nunca havia sido utilizado em sessões anteriores, para que fosse possível avaliar a generalização das respostas ensinadas para novos objetos.

O procedimento envolveu duas etapas de ensino. A primeira etapa consistiu no ensino de topografias de mando. O ensino de um conjunto diverso de topografias era condição para a segunda etapa, o ensino de variação.

\section{Etapa I. Ensino de Topografias de Mando}

O delineamento experimental utilizado foi o de Linha de Base Múltipla.

Fase 1. Linha de Base. Foram realizadas três sessões de linha de base e cada sessão teve 10 tentativas. Em cada tentativa, o experimentador, sentado em frente ao participante, após contato visual apresentava um item selecionado no teste de preferência. Durante 10 segundos, caso ele emitisse um mando solicitando o objeto, o experimentador entregava o objeto e o participante poderia ficar com o objeto por 10 segundos, logo após uma nova tentativa tinha início.

Fase 2. Ensino de cinco topografias de mando. Cinco topografias de mandos foram ensinadas para P1 e quatro para P2: 1. "Posso pegar (nome do objeto)?"; 2. "Quero (nome do objeto)"; 3. "Dá pra mim (nome do objeto)?"; 4. "Me empresta (nome do objeto)?" e 5. "Posso brincar (nome do objeto)?".

Cada sessão de ensino teve 25 tentativas, sendo 10 de linha de base e 15 de ensino. Nas tentativas de ensino, o experimentador sentava-se na frente da criança e após contato visual, era apresentado um item de preferência da criança. Era apresentado um modelo do mando que a criança deveria ecoar e, a seguir, ocorria a retirada gradual (fading out) do modelo verbal.

Foram realizados quatro níveis de fading do modelo verbal. No nível I de fading, após 10 segundos, o experimentador dava o modelo verbal total (MT), "Posso pegar (nome do objeto)?", e esperava 5 segundos. Se a criança ecoasse, o experimentador fazia um elogio e permitia o acesso ao item por 10 segundos. Essa consequência foi utilizada para todos os níveis de fading. Caso o participante não ecoasse o modelo verbal, o experimentador repetia até três vezes o modelo total e apresentava uma instrução adicional: "fale igual" ou "repita comigo". O critério para passar para o próximo passo de fading era o participante ecoar corretamente em quatro tentativas da sessão. Era possível mudar de nível de fading na mesma sessão. Este critério foi utilizado em todos os níveis do fading. No nível II de fading, parte do modelo verbal era apresentada, Posso pegar (...)? - intraverbal intermediário (II). Se o participante não apresentasse o mando completo em 10 segundos, o experimentador voltava um passo, para o nível I nessa tentativa. Se o participante emitisse a resposta verbal esperada, o experimentador consequenciava a resposta como descrito. Se durante três tentativas seguidas com esse nível de ajuda o participante não respondesse corretamente, a tentativa seguinte era 
iniciada com o nível anterior de ajuda (MT). No nível III de fading, era apresentada parte menor que dado no nível II do modelo verbal Posso (...)? - intraverbal mínimo (IM). Caso o participante não apresentasse o mando em 10 segundos, o experimentador fornecia novamente o IM. Se o participante não respondesse, voltava-se um nível de fading (II). No nível IV, o experimentador apresentava o objeto e o participante deveria emitir a resposta de mando sob controle apenas do objeto. O critério para passar para o ensino da próxima topografia era emitir três respostas corretas para cada um dos cinco itens.

Fase 3. Testes de Generalização. Nos testes de preferência que ocorriam antes de cada sessão de ensino, em algumas tentativas, foram apresentados objetos novos, ou seja, o teste foi planejado de forma a que pudesse ser selecionado um dos cinco objetos para a sessão de ensino que nunca havia sido utilizado em uma sessão anterior. Isto permitiu avaliar se ocorria generalização do mando na topografia que estava sendo ensinada para um novo objeto. Se na primeira tentativa que o objeto novo era apresentado o participante emitisse, nos 10 segundos que ocorriam antes da apresentação do modelo o mando para aquele objeto, foi considerado que houve generalização da topografia ensinada para um novo objeto. Ao longo das sessões de ensino de cada topografia, em função das escolhas dos participantes e da quantidade de sessões necessárias para completar o ensino da topografia, o número de objetos novos variou entre três e cinco.

Além dessas avaliações ao longo das sessões de ensino, no final do ensino da terceira, quarta e quinta topografias, foram realizadas sessões exclusivas de testes de generalização em que todos os 10 objetos apresentados no teste de preferência eram novos. Caso ele emitisse qualquer topografia solicitando o objeto - ensinadas, novas ou uma topografia que recombinasse os mandos ensinados -, era-lhe entregue o objeto acompanhado de reforçamento social. Caso não emitisse nenhum mando, o objeto era guardado e era iniciada uma nova tentativa.

\section{Etapa 2. Ensino de Variação}

Fase 1: Ensino de variabilidade - Lag 1. As sessões eram semelhantes às da fase anterior. Foram realizadas 25 tentativas em cada sessão, todas de ensino de variação. A diferença foi que, nesta etapa, as respostas de mando só eram consequenciadas com o elogio e acesso ao objeto solicitado se ele emitisse um mando, após a primeira tentativa da sessão, com uma topografia diferente da resposta emitida na tentativa anterior (Lag 1). Se o participante emitisse a mesma topografia emitida na tentativa anterior, o experimentador esperava até 20 segundos para que o participante emitisse uma resposta com outra topografia; durante esse intervalo o experimentador não interagia com o participante. Se o participante emitisse uma resposta com outra topografia (ensinada ou nova, dentro do contexto), o experimentador consequenciava com um elogio e a entrega do item. Se o participante continuasse emitindo a mesma topografia durante os 20 segundos, o experimentador dizia "O que mais você pode dizer agora". Mas se mesmo com essa pergunta o participante continuasse emitindo a mesma topografia, o experimentador introduzia o nível III de fading - Intraverbal Mínimo - de uma resposta ensinada de outra topografia, variada em relação à que o participante emitiu. Caso em três tentativas seguidas esse nível de fading não fosse suficiente para que o participante emitisse uma resposta considerada correta, o nível de fading - Intraverbal Intermediário - era introduzido na tentativa seguinte. Estas respostas eram registradas como não variadas. Quando o participante emitisse cinco respostas corretas consecutivas, ou seja, se em cinco tentativas seguidas ele variasse a topografia da resposta em relação à tentativa anterior a fase era encerrada.

Fase 2. Ensino de variabilidade - Lag 2. O procedimento foi igual ao da Fase 1, porém o participante só recebia o elogio e o acesso ao item se ele emitisse uma resposta correta e variada em relação à duas tentativas anteriores.

Fase 3. Ensino de variabilidade - Lag 3. O procedimento foi igual ao da Fase 1, porém o participante só recebia o elogio e o acesso ao item se ele emitisse a resposta correta e variasse em relação às três tentativas anteriores.

\section{Resultados}

O número de respostas emitidas frente aos objetos apresentados sem um estímulo verbal antecedente durante as sessões de ensino das cinco topografias (P1, painéis à esquerda) ou quatro topografias ( $\mathrm{P} 2$, painéis à direita), utilizando o procedimento de linha de base múltipla, é representado na Figura 1. Em cada painel, estão as respostas de uma topografia. As linhas pontiIhadas indicam o início do ensino de cada topografia e os quadrados destacados em preto marcam as sessões em que foi testada a generalização. 
Procedimento para ensino de mandos e para promover variação na topografia das respostas em crianças autistas
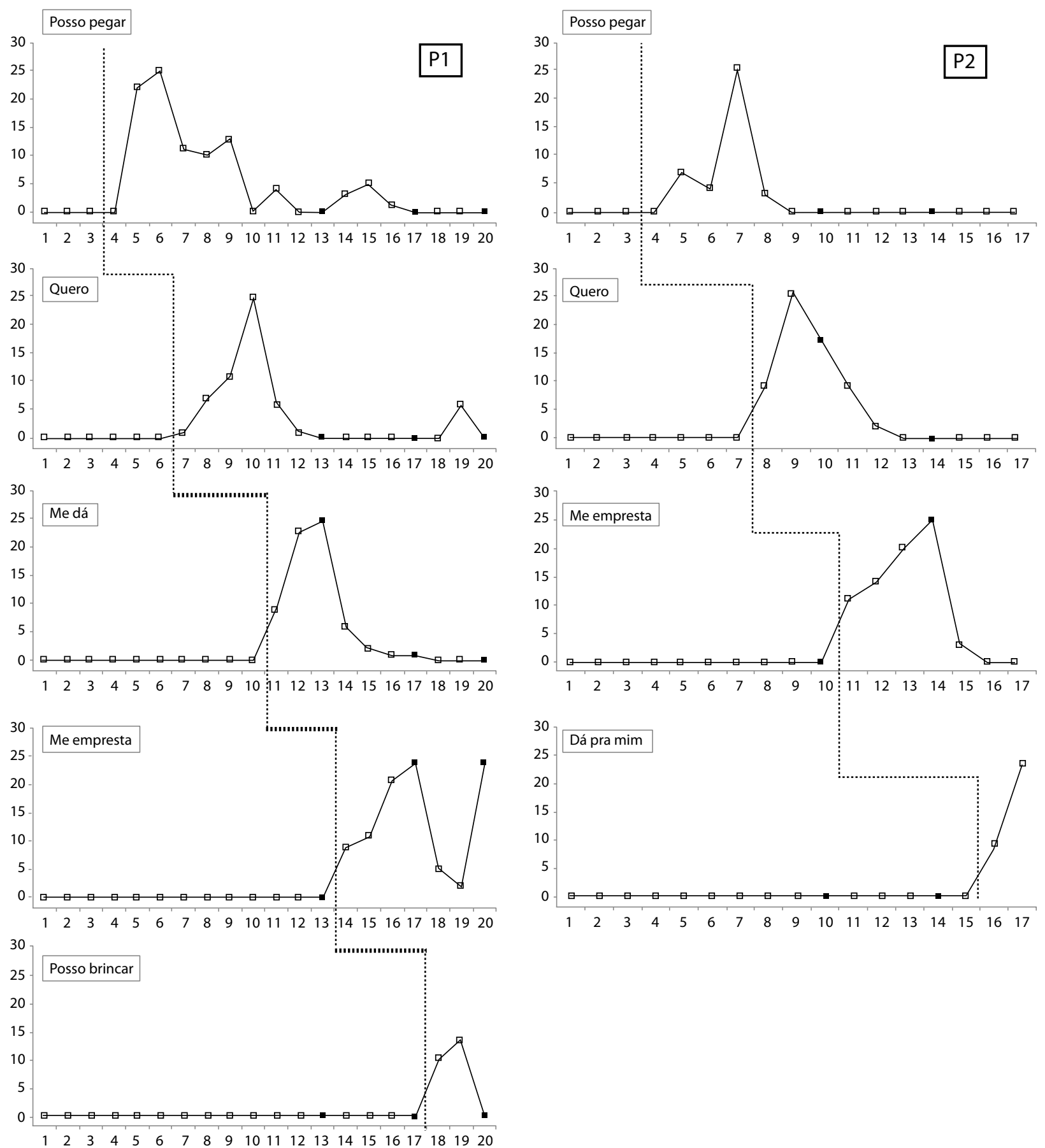

Figura 1. Número de Respostas sem Modelo Verbal Emitidas em Cada Topografia Ensinadas ao Longo das Sessões. As Linhas Pontilhadas Indicam o Início do Ensino de Cada Nova Topografia e os Quadrados em Pretos Sinalizam as Sessões de Teste de Generalização.

Em geral, observa-se que o número de respostas da topografia ensinada aumenta ao longo das sessões, a partir do momento em que o procedimento de ensino é iniciado e, à medida que uma nova topografia é ensinada, o número de resposta da topografia anteriormente ensinada diminui e a da que está sendo ensinada aumenta, progressivamente.
Durante o ensino das topografias, foram utilizados diferentes níveis de fading do modelo verbal: 1. ecóico, 2. intraverbal intermediário, 3. intraverbal mínimo e 4. resposta frente ao objeto apresentado sem o modelo verbal. O procedimento de fading permitiu ensinar cinco ou quatro topografias de respostas de mando solicitando objetos que passaram a ocorrer 
sem um modelo verbal anterior. No ensino da primeira topografia, foram utilizados todos os níveis de fading; a partir do ensino da segunda, geralmente, foram necessários apenas dois níveis, o intraverbal mínimo e o sem modelo verbal, já que os participantes aprendem as topografias mais rapidamente, diminuindo o número de sessões para atingir o critério de encerramento do ensino de quatro para três.

A generalização da emissão de mando para novos objetos pôde ser avaliada de duas formas. Uma, durante as sessões de ensino nas tentativas em que novos objetos eram apresentados. Outra forma, durante as três sessões exclusivas de teste de generalização, em que todos os objetos apresentados eram novos. Na Figura 2 , está representado o número de respostas em que houve generalização da resposta ensinada para novos objetos em todas as sessões de ensino de cada topografia ( $T$ ) e de ensino da variação (Lag) e durante as três sessões de teste de generalização (TG). A linha pontiIhada representa o número de oportunidades que os participantes tiveram durante cada fase e as barras representam número de vezes os participantes generalizaram os mandos para novos objetos. De maneira geral, na maioria das vezes em que foram apresentados novos objetos, ocorreu generalização dos mandos ensinados para esses objetos: para P2 em todas as oportunidades e para P1 em 37 das 40 oportunidades.

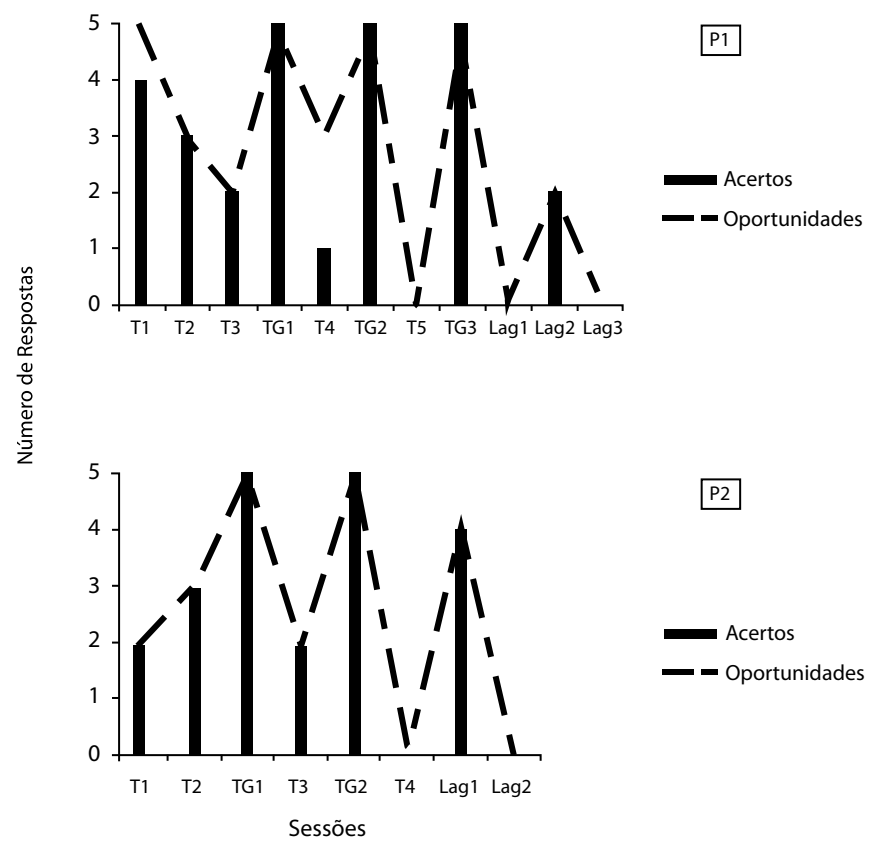

Figura 2. Respostas Certas Emitidas Durante a Apresentação de Objetos Novos Durante as Cinco Primeiras Tentativas de Cada Sessão e em Cada Fase. As Letras (T) Sinalizam as Topografias e (TG) os Testes de Generalização.
Verifica-se que, em todos os testes de generalização, os participantes emitiram os mandos para os novos objetos. Nos dois primeiros testes, após a terceira e a quarta topografia, os mandos emitidos pelos participantes eram os da topografia que tinha acabado de ser ensinadas, possivelmente devido ao fato que quando era ensinada uma nova topografia, as topografias anteriores não eram reforçadas. Contudo, no último teste de generalização, que ocorreu após o ensino da quinta topografia, P1 emitiu mandos referentes à quarta topografia.

Ao final da Fase 2 de ensino, os participantes emitiam mandos tanto para objetos ensinados como para novos objetos. Apesar do procedimento de ensino de topografias, planejado para propiciar recombinação de respostas verbais, ter permitido estabelecer diversas topografias de mando e estas ocorrerem para novos objetos, ao final dessa fase, as solicitações eram feitas, em geral, com uma única topografia na sessão, a última ou a penúltima ensinada (Figura 1).

Teve início, então, a Etapa 2 de ensino de variabilidade durante o qual, nas Fases 1 e 2, utilizou-se o procedimento Lag 1 e Lag 2, respectivamente, para ambos os participantes. Foram necessárias duas sessões, na Fase 2, para $\mathrm{P} 1$ atingir o critério e uma para P2. A Fase 3 foi realizada apenas por $\mathrm{P} 1$ e o procedimento utilizado foi o Lag 3. Na Figura 3, está representado o número de respostas em cada topografia emitidas nas sessões em que vigoraram os diferentes valores de Lag. No painel superior, estão as topografias emitidas por P1 e no inferior, as emitidas por P2. Observa-se, ao longo do ensino de variabilidade, que houve um grande aumento do número de topografias emitidas, 11 para P1 e nove para P2.

$P 1$, na sessão 1 em que vigorou o esquema de reforçamento Lag 1, emitiu quatro topografias diferentes, 11 respostas com as topografias "Me emprestam..." e "Me dá..." (Figura 3), sendo a primeira uma topografia ensinada e a segunda uma recombinação de topografias ensinadas previamente. As outras topografias emitidas foram "Por favor me dá..." e "Dá..." que apareceu somente em uma e duas ocorrências, respectivamente.

O Lag 2 vigorou, para P1, na sessão 2 e 3 . Na sessão 2, observa-se que as topografias emitidas no Lag 1 ("Me empresta..." e "Me dá...") também foram emitidas no Lag 2, porém em um número menor, nove e sete respostas, respectivamente. E outras três topografias começaram a ser emitidas, "Quero..." com maior ocorrência (7) e "Pode dar..." e "Por favor dá pra mim...", (com uma resposta). Na sessão 3, o padrão emitido 
por P1foi bem parecido com o da sessão 2, sendo as topografias mais emitidas "Me empresta..."; "Me dá..." e "Quero...", as duas primeiras com oito respostas e a última com sete respostas. Outra topografia foi emitida "Por favor eu quero...", esta com um autoclítico 'por favor' adicionado.
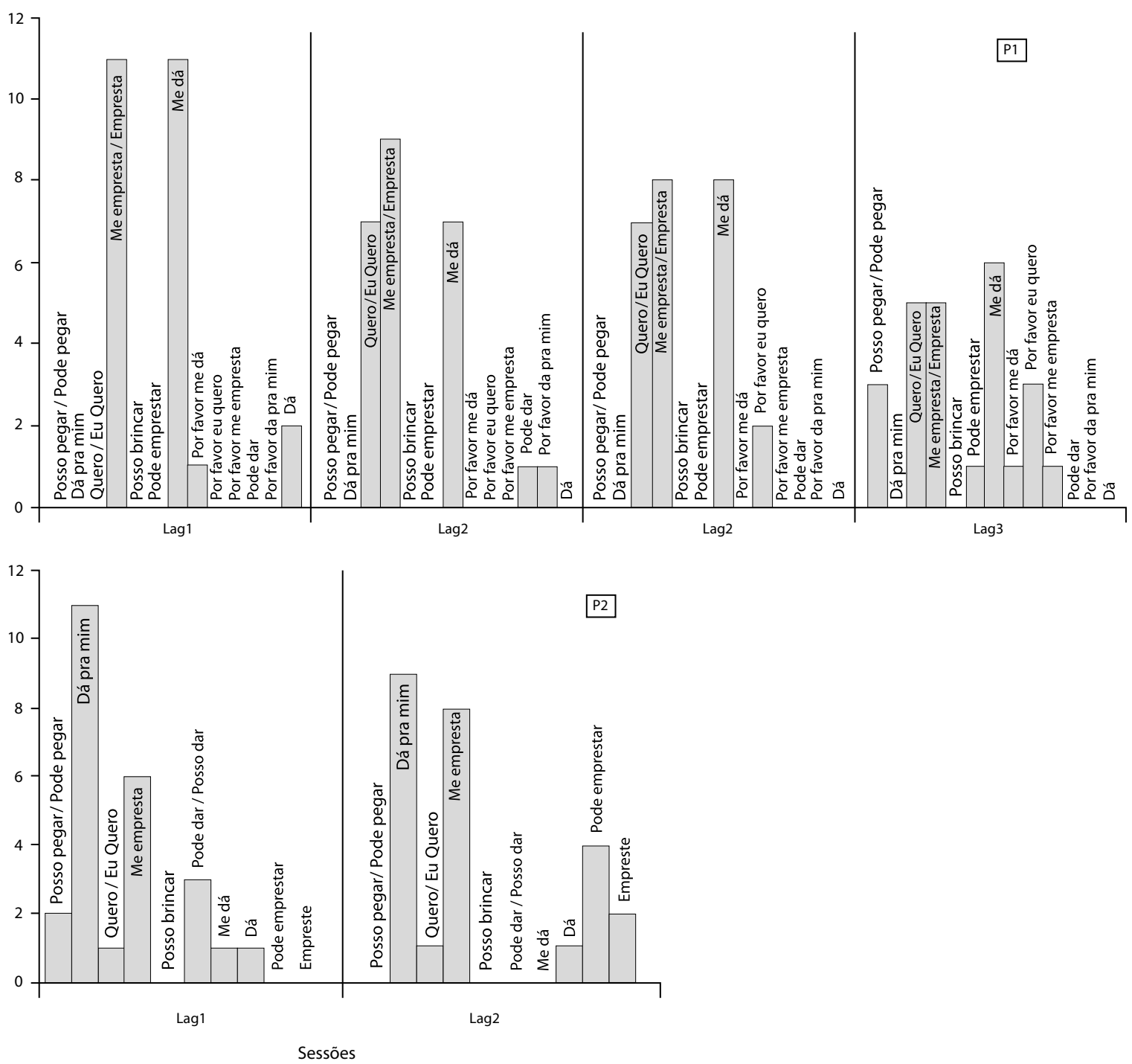

Figura 3. Número de Respostas com Cada Topografia Emitida durante as Sessões de Lag.

Quando vigorou o Lag 3, na sessão 4, houve um aumento grande do número de topografias, de quatro, na sessão 3, para oito. Topografias emitidas nas sessões anteriores, "Me empresta..." (cinco); "Me dá..." (seis); "Quero..." (cinco) e "Por favor eu quero..." (três), se mantiveram. E outras quatro topografias começaram a ser emitidas: "Posso pegar..." (três), e "Por favor me empresta...", "Pode emprestar", "Por favor me dá..." (uma vez). Observa-se que à medida que o Lag aumenta, diminui a concentração de respostas em poucas topografias e aumenta o número de respostas em diversas topografias. Para ambos os participantes, no Lag 1, duas respostas têm maior ocorrência, no Lag 2, três têm maior ocorrência. Para P1, no Lag 3, cinco topografias têm maior ocorrência. Diminui a quantidade de ocorrência de topografias muito emitidas anteriormente e aumenta o número de topografias diferentes. Há um achatamento e uma maior dispersão das respostas em várias topografias, indicando um aumento da variação.

P2 emitiu nas sessões de Lag 1 e 2 um número grande de respostas: sete e seis diferentes topografias de respostas, respectivamente. Das sete, duas topografias ensinadas têm maior número de ocorrência: "Dá 
pra mim..." (11) e "Me empresta..." (seis); essas foram também as mais emitidas na sessão de Lag 2. A concentração de respostas em uma delas "Dá para mim" diminui um pouco com o aumento da exigência do Lag 2, ou seja, há um achatamento das barras, apesar de ser menor que em P1. Além dessas, ainda tiveram duas topografias emitidas na sessão de Lag 1 e na sessão de Lag 2, "Quero..." e "Dá..." (uma resposta cada). Três topografias emitidas na sessão 1 não foram emitidas na sessão 2, e duas novas topografias na sessão de Lag 2. Com o aumento do Lag para 3, aumenta a dispersão, como ocorre com P1.

$\mathrm{Na}$ Figura 4, é apresentada a porcentagem das respostas (ensinadas, recombinadas e novas) emitidas nas sessões de Lag. As recombinadas são compostas por partes de duas topografias ensinadas, e.g.: "Pode emprestar..." e "Me dá...". As respostas novas são as não ensinadas.

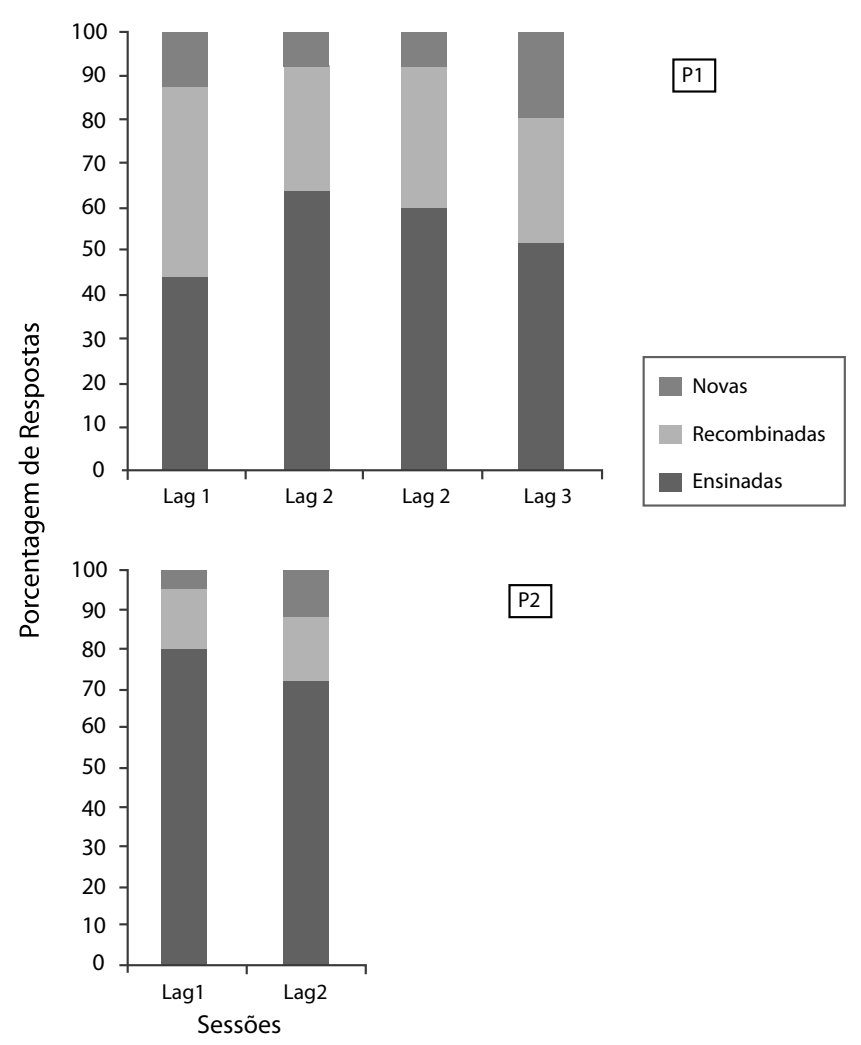

Figura 4. Porcentagem de Respostas Ensinadas, Recombinadas e Novas Durante as Sessões de Lag.

As respostas ensinadas ocorreram, em geral, em mais de $50 \%$ das tentativas durante as sessões de ensino de variabilidade. Para P1, as topografias ensinadas foram emitidas entre 45 e $65 \%$ das respostas e para P2 entre
72 e $80 \%$ das respostas. O segundo conjunto de resposta com maior porcentagem foram as recombinadas. Para $\mathrm{P} 1$, as respostas recombinadas variaram em torno de $28 \%$ a $44 \%$, sendo que na sessão 1 foi muito próxima da porcentagem de respostas ensinadas (45\%). Na sessão de Lag 3, houve um aumento nas respostas novas (de $10 \%$ e $9 \%$ nas no Lag 1 e 2, respectivamente, para $20 \%$, no Lag 3). Para P2 as respostas recombinadas foram $16 \%$, nas duas sessões. $E$ as novas ocorreram em 4 a $12 \%$ das sessões de Lag 1 e 2, respectivamente. Para ambos os participantes as novas respostas tiveram aumento exatamente quando o Lag estava em seu maior valor.

Para P1, as respostas novas, quatro das seis, envolveram a adição de um autoclítico que não foi ensinado, por exemplo, "Por favor me dá..."; "Por favor eu quero..."; "Por favor me empresta..." e "Por favor dá pra mim....". Nas três últimas respostas, ocorre só a adição do autoclítico às topografias que haviam sido ensinadas, porém a primeira resposta, além da adição do autoclítico, o participante coloca o "me" que havia sido ensinado na topografia "Me empresta..." e o "dá", que foi ensinado na topografia "Dá pra mim...". As outras duas topografias novas, "Pode dar..." e "Dá...", têm em sua constituição partes de topografias ensinadas, mas que sozinhas, essas partes, são diferentes e novas em relação às topografias que foram ensinadas, pois a primeira é uma construção totalmente nova do participante.

\section{Discussão}

Buscou-se avaliar um procedimento de ensino de mando planejado de forma a tornar mais provável uma ampliação do repertório e alterar padrões estereotipados de comportamento verbal de crianças autistas. Uma vez que um repertório básico, não excessivamente restrito, é condição necessária para que a variação possa ser ensinada, um procedimento de fading do modelo verbal foi utilizado para ensinar topografias de mando. Assim como nos estudos de Williams et al. (2000) e Romano (2014), os resultados indicaram que o procedimento de fading foi eficaz para a instalação das topografias de mando, sem que fosse necessário passar por todos os níveis de fading para que os participantes emitissem respostas sob controle dos objetos apresentados, sem um modelo verbal. Observa-se que, ao longo do ensino, diminui em geral o número total de tentativas para concluir o ensino de cada topografia, e ao ensinar uma topografia, a anteriormente aprendida passa a ocorrer menos.

O planejamento do procedimento de ensino permitiu que o participante ao responder combinasse o mando ensinado com pelo menos cinco objetos em cada sessão. Os 
testes de preferência que antecederam as sessões, planejados de forma a possibilitar que em muitas sessões de ensino novos objetos pudessem ser escolhidos pelos participantes, permitiram avaliar, na primeira tentativa em que o objeto novo era apresentado, se a criança emitia a topografia que estava sendo ensinada frente a um novo objeto. Isto foi possível também nas sessões de generalização em que todos os objetos eram novos. Em geral, houve recombinação entre a topografia ensinada e os novos objetos, na maioria das tentativas em que isto foi testado (Figura 2), evidenciando que as respostas não ficaram sob controle específico dos estímulos que estavam sendo ensinados, mas que ocorreu generalização para estímulos não ensinados por recombinação, tal com proposto por Striefel e Wetherby (1973). Tal recombinação envolve possivelmente abstrações de unidades no mando ensinado e combinação dessas unidades com novos estímulos, no caso, objetos novos. Tal como no estudo de Goldstein (1983), em que crianças recombinaram nomes dos sujeitos com novas ações, no presente estudo os participantes recombinaram topografias de mando com novos objetos formando novos mandos. $\mathrm{Na}$ etapa de ensino de topografias de mando, geralmente a recombinação ocorreu do objeto com a última topografia ensinada. Assim, ao final do procedimento de ensino de topografia, apesar de novos mandos terem sido ensinados, a topografia emitida era, em geral, a última reforçada.

Crianças autistas, geralmente, necessitam de planejamento de contingências de reforçamento especiais para adquirirem um comportamento verbal variado, com procedimentos voltados para alterar repertórios estereotipados e gerar variação comportamental. Foi avaliado então se um procedimento de ensino, com reforçamento diferencial do variar (Lag 1 ao 3), em que havia um aumento gradativo da exigência de variabilidade produziria respostas variadas. O reforçamento diferencial do variar alterou o padrão estereotipado do responder dos dois participantes. Ambos, que no início do procedimento não emitiam mandos (como pode ser visto na linha de base da Figura 1) e que ao final do ensino das cinco topografias emitiam apenas a quinta topografia ensinada, passaram a emitir várias topografias, após o ensino do variar.

Os dados do aumento da variabilidade com o reforçamento direto do variar convergem com os estudos de Lee et al. (2002), Lee e Sturney (2006) e Esch et al. (2009) que utilizaram o esquema de reforçamento Lag 1. Esses autores identificaram que com Lag 1 os participantes, em geral, variavam entre duas topografias, tal como ocorreu no presente estudo.

Susa e Schilinger (2012), que aumentaram progressivamente o Lag, identificaram aumento da variabilidade com o aumento do Lag. No presente estudo, observou-se resultados semelhantes. Com o aumento do Lag, há uma menor concentração em poucas topografias, há uma maior distribuição de respostas por várias topografias: P1 chegou a emitir 13 topografias diferentes de respostas e P2, dez. (Figura 3). No caso de P1, maior número de diferentes topografias ocorreu quanto maior o Lag.

A análise das diversas topografias emitidas na fase de ensino do variar indica que a variação ocorre com base em repertórios construídos. Observa-se que predominantemente o material sobre o qual a variação ocorre são as respostas ensinadas, geralmente elas estão entre 50 e $60 \%$ das respostas para $\mathrm{P} 1$ e entre 70 e $80 \%$ para $\mathrm{P} 2$. Os dados mostram também a importância da variação gerada por generalização recombinativa, que foram entre 44 e $16 \%$ das respostas. Após o ensino de variabilidade, é que passaram a ocorrer respostas recombinadas formadas por partes de diferentes topografias. Por exemplo, depois de ensinadas as topografias "me empresta" e "dá para mim" o participante emite a topografia "Me dá...". Possivelmente há um controle de estímulos por partes da frase, por meio de abstração, e uma recombinação das partes abstraídas em uma topografia nunca antes ensinada, formada por generalização recombinativa (Figuras 3 e 4). Assim, a recombinação produziu uma nova topografia, embora seus componentes façam parte de relações previamente aprendidas. Resultados semelhantes foram obtidos por de Striefel e Wetherby (1973) e Hanna et al. (2011). Topografias ensinadas foram combinadas, também, com autoclíticos, como "por favor, eu quero", um repertório construído compondo repertório pré-experimental. Ocorreram ainda respostas novas que nunca haviam sido ensinadas.

Em suma, o procedimento proposto possibilitou a instalação de mando para solicitar objetos, produzindo uma ampliação deste repertório. Tal ampliação pode ter sido favorecida pelo fato de que a todo tempo, com o uso de inúmeros objetos, selecionados nos testes de preferência, o procedimento levar o participante a combinar e consequentemente variar a topografia com vários novos objetos. O procedimento pode ter favorecido, por meio de uma história de reforçamento, o comportamento de relacionar e recombinar. Quando o variar foi reforçado, se produziu variação tendo como material básico o repertório ensinado, que permitiu variação.

Em novos estudos, seria importante avaliar a extensão destes resultados para outros operantes verbais e testar a generalidade da variação que pode ser produzida com este procedimento para outros ambientes, em situações não estruturadas, para verificar se ela passa a ocorrer. 


\section{Referências}

DeLeon, I. G., \& Iwata, B. A. (1996). Evaluation of a multiple-stimulus presentation format for assessing reinforcer preferences. Journal of Applied Behavior Analysis, 29(4), 519-533. doi: 10.1901/ jaba.1996.29-519

Esch, J. W., Esch, B. E., \& Love, J. R. (2009). Increasing vocal variability in children with autism using a lag schedule of reinforcement. The Analysis of Verbal Behavior, 25, 73-78. Recuperado de https://www. ncbi.nlm.nih.gov/pmc/articles/PMC2779075/pdf/anvb-25-01-73.pdf

Goldstein, H. (1983). Recombinative generalization: relationships between environmental conditions and the linguistic repertoires of language learners. Analysis and Intervention in Developmental Disablities, 3, 279-293. doi: 10.1016/0270-4684(83)90002-2

Hanna, E. S., Kohlsdorf, M., Quinteiro, R. S., Melo, R. M., De Souza, D. G., De Rose, J. C., \& Mcllvane, W. J. (2011). Recombinative reading derived from pseudoword instruction in a miniature linguist system. Journal of Experimental Analysis of Behavior, 26, 76-89. doi: 10.1901/jeab.2011.95-21

Lee, R., McComas, J. J., \& Jawor, J. (2002). The effects of differential and lag reinforcement schedules on varied verbal responding by individuals with autism. Journal of Applied Behavior Analysis, 35, 391-402. doi: 10.1901/jaba.2002.35-391

Lee, R., \& Sturmey, P. (2006). The effects of lag schedules and preferred materials on variable responding in students with autism. Journal of Autism and Developmental Disorders, 36(3), 421-428. doi: 10.1007/ s10803-006-0080-7

Lee, R., Sturmey, P., \& Fields, L. (2007). Schedule-induced and operant mechanisms that influence response variability: A review and implications for future investigations. The Psychological Record, 57, 429-455. doi: 10.1080/00221325.1965.10532758

Matson, J. L., Sevin, J. A., Box, M. L., Francis, K. L., \& Sevin, B. M. (1993). An evaluation of two methods for increasing self-initiated verbalization in autistic children. Journal of Applied Behavior Analysis, 26, 389-398. doi: 10.1901/jaba.1993.26-389

Neuringer, A., Deiss, C., \& Olson, G. (2000). Reinforced variability and operant learning. Journal of Experimental Psychology: Animal Behavior Processes, 26(1), 98-111. doi: 10.1037/0097-7403.26.1.98

Romano, C. (2014). A produção de variabilidade em respostas intraverbais de crianças com autismo e seleção de respostas novas. (Dissertação de Mestrado). Recuperado de https://tede2.pucsp.br/ handle/handle/16727

Schreibman, L., Dawson, G., Stahmer, A. C., Landa, R., Rogers, S. J., Mcgee, G. G., ... Halladay, A. (2015). Naturalistic developmental behavioral interventions : Empirically validated treatments for autism spectrum disorder. Journal of Autism and Developmental Disorders, 2411-2428. doi: 10.1007/s10803-015-2407-8

Skinner, B. F. (1957). Verbal behavior. Englewood Cliffs: Prentice-Hall.

Striefel, S., \& Wetherby, B. (1973). Instruction-following behavior of a retarded child and its controlling stimuli. Journal of Applied Behavior Analysis, 6, 663-670. doi: 10.1901/jaba.1973.6-663

Sundberg, M. L., \& Michael, J. (2001). The benefits of Skinner's analysis of verbal behavior for children with autism. Behavior Modification, 25(5), 698-724. doi: 10.1177/0145445501255003

Susa, C., \& Schlinger, H.D. (2012). Using a lag schedule to increase variability of verbal responding in an individual with autism. The Analysis of Verbal Behavior, 28(1), 125-30. Recuperado de https://www.ncbi.nlm. nih.gov/pmc/articles/PMC3363399/pdf/anvb-28-01-125.pdf

Taylor, B. A., \& Harris, S. L. (1995). Teaching children with autism to seek information: acquisition of novel information and generalization of responding. Journal of Applied Behavior Analysis, 28, 3-14. doi: 10.1901/jaba.1995.28-3

Williams, G., Donley, C. R., \& Keller, J.W. (2000). Teaching children with autism to ask questions about hidden objects. Journal of Applied Behavior Analysis, 33, 627-630. doi: 10.1901/jaba.2000.33-627

1. Os dados referem-se a pesquisa de mestrado da primeira autora sob a orientação da segunda autora. O mestrado foi parcialmente financiado pela CAPES.

Mariana Chernicharo Guimarães, Mestre em Psicologia

Experimental: Análise do Comportamento pela Pontifícia

Universidade Católica de São Paulo (PUC-SP), é Doutoranda em análise do comportamento pela Western New England University U.S. e Professora no New England Center for Children - U.S. E-mail: marianachernicharo@gmail.com

Nilza Micheletto, Doutora em Psicologia Social pela Pontifícia Universidade Católica de São Paulo - PUC-SP, é Professora

Titular do Departamento de Métodos e Técnicas em Psicologia

da Faculdade de Ciências Humanas e da Saúde da Pontifícia

Universidade Católica de São Paulo (PUC-SP). Endereço para correspondência: Pontifícia Universidade Católica de São Paulo,

Faculdade de Psicologia, Laboratório Experimental. Rua João Ramalho, 301, Perdizes. CEP: 05008-000 - São Paulo, SP - Brasil. Telefone: (11) 36708192. Fax: (11) 36708386. E-mail: nimicheletto@uol.com.br

Recebido em 06.Jun.16 Revisado em 02.Jan.18

Aceito em 20.Mar.18 